\title{
Predictive torque control of electric vehicle
}

\author{
Mohammed El Amin Abdelkoui, Abdeldjebar Hazzab \\ Laboratoire de Recherche Commande, Analyse et Optimisation des Systèmes Electro-énergétiques, \\ Université TAHRI Mohamed de Bechar, Algeria
}

\begin{tabular}{l}
\hline \hline Article Info \\
\hline Article history: \\
Received Dec 25, 2018 \\
Revised Mar 25, 2019 \\
Accepted Apr 4, 2019 \\
\hline
\end{tabular}

Keywords:

Driving wheels

Electronic differential

Electric vehicle (EV)

Induction machine (IM)

Predictive torque control

\begin{abstract}
The following article represents the development of a traction system of an electrical vehicle $(\mathrm{EV})$ that consist of two Three-phase squirel-cage induction motors (IM) that permit the drive of the two front driving wheels. The two motors are controlled using the Predictive Torque Control (PTC) method; A technique based on the next step prediction and evaluation of the electromagnetic torque and stator flux In a cost function in order to determinate the inverter switching vector that minimize the error between references and predicted values. PTC is what we tried to underline in this paper, so we explain below the principle of the method; and the system mathematical description is provided. An electronic differential is applied on the system to control independently the speed of the two wheels at different operating conditions in order to characterize the driving wheel system behavior, the robustness in steady state and in transient state.
\end{abstract}

Copyright $@ 2019$ Institute of Advanced Engineering and Science. All rights reserved.

\section{Corresponding Author:}

Mohammed El Amin Abdelkoui, Laboratoire de Recherche Commande, Analyse et Optimisation des Systèmes Electro-énergétiques, Université TAHRI Mohamed, BP 417, Bechar (08000), Algeria.

Email: dr.abdelkoui@gmail.com

\section{INTRODUCTION}

Electric vehicles (EV) have gained increasing popularity over the last decade in the automotive sector, it represents a new alternative towards which to turn to ensure preservation of the environment by reducing emissions caused by the use of internal combustion engine vehicles (ICVs), and solving energy problems due to the depletion of fossil fuels [1,2]. The development of (EV's) has known a significant advanced and get enough performance, boosted by the big improvement and development of electric motors, batteries, and high control technologies. However, the most remarkable advantage of the EV is that we can control the motor torque much more quickly and precisely comparing with conventional (ICV's) [3, 4]. Induction machines (IM) are widely used in (EV) applications due to their low cost and high performances and robustness and also for their high starting torque.

The Direct Torque Control (DTC) replaces the field oriented control (FOC) in high dynamic applications, this method requires neither a modulator nor an internal current PI controller. These features make the system implementation easier and lead to a fast dynamic response. However, due to its structure, the main problems of this strategy are the high level of torque and flux ripples and the variable switching frequency. Which can lead to decrease the control performances; and increase noises and control difficulty at low speed [5-7]. In the last few decades, various methods were proposed to overcome these drawbacks, such as multilevel converters, artificial intelligence techniques and fixed switching frequency modulation techniques like the space vector modulation (SVM), those techniques always Increase the control algorithm complexity leading to an extensive software/hardware computational requirement [8].

The model predictive control (MPC) method has increased its study and research since its introduction into the field of electrical engineering in the 1980 s by researchers linked to academia and 
industry, MPC is mainly used to increase the efficiency and performance of system's responses and to solve problems of automation and control of a wide range of devices and industrial processes that present a complex nature [9], MPC concept uses a system model to predict the future system states in discrete time steps. Recently, predictive torque control (PTC) strategies have received wide attention in research communities due to their intuitive features, easy implementation, and easy inclusion of nonlinearities and constraints of model predictive control (MPC) [10, 11]. It is a technique based on DTC control principles on the one hand; and on the prediction of the stator current and flow using the MPC methods on the other hand, to allow the calculation of the torque in the next instant, and also to prevent the future behavior and reaction of the system in order to increase its performance.

Electric vhicles control techniques are vast field and there is too many methods that may be either slow performance or expencive equipment however in the work that follows a simulation under matlab/Simulink of PTC integration for the control of two induction machines ensuring the traction of an electric vehicle is presented. This technique allows estimation and the next step prediction of the driving parameters when changing resistive torque or driving condictions are applied, it permits to anticipate changes and react quickly in order to provide a better control for the driver, faster acceleration and greater stability of the EV.

This paper is structured as follows: in section II, the mathematical model of an induction machine (IM) and the applied voltage source inverter are presented. In section III, the vehicle model is presented as well as the charges and resistive torques equations. In section IV, the PTC method is explained. Section V presents the results and the corresponding analysis. Finally, the conclusions are given in section VI.

\section{INDUCTION MACHINE AND INVERTER'S MODELS}

The machine considered in this paper, is a three-phase squirrel-cage induction machine. The mathematical model of an induction motor can be expressed by the following equations [11]:

$$
\begin{aligned}
& v_{s}=R_{s} \cdot i_{s}+\frac{d}{d t} \psi_{s} \\
& 0=R_{r} \cdot i_{r}+\frac{d}{d t} \psi_{r}-j \cdot w \cdot \psi_{r} \\
& \psi_{s}=L_{s} \cdot i_{s}+L_{m} \cdot i_{r} \\
& \psi_{r}=L_{r} \cdot i_{r}+L_{m} \cdot i_{s} \\
& T=\frac{3}{2} \cdot p \cdot \operatorname{lm}\left\{\psi_{s}^{*} \cdot i_{s}\right\} \\
& j \frac{d \omega_{m}}{d t}=T_{e}-T_{l}
\end{aligned}
$$

where $v_{s}$ is the stator voltage vector; $i_{s}$ and $i_{r}$ are the stator and rotor currents. $\psi_{s}$ and $\psi_{r}$ represent the stator flux and rotor flux, respectively. $R_{s}$ and $R_{r}$ are the stator and rotor resistances. $L_{s}, L_{r}$ and $L_{m}$ are stator, rotor and mutual inductance, respectively, and $\omega$ is the electrical speed. $p$ is the number of pole pairs, and $T$ denotes the electromagnetic torque.

The topology of the two-level voltage source inverter applied in this work for the PTC and its feasible voltage vectors are presented in Figure 1.
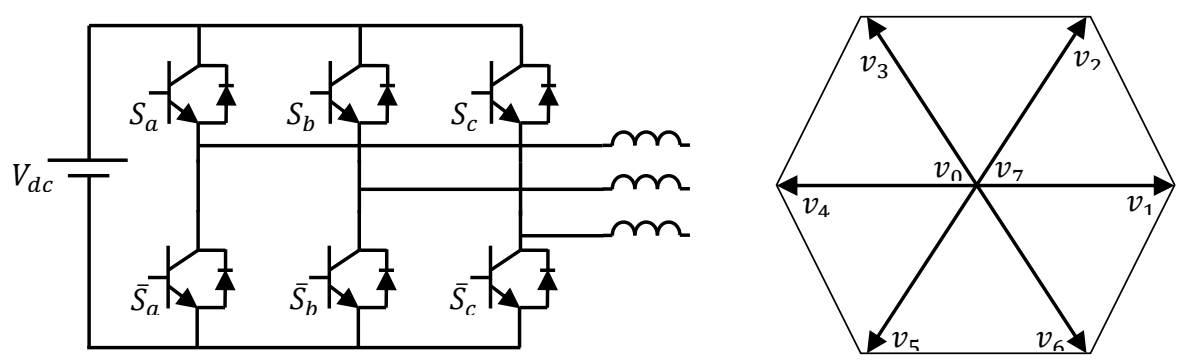

Figure 1. Left: Two-level voltage source inverter, Right: Voltage vectors 
The switching state $\mathrm{S}$ can be expressed by the following vector [7]:

$$
S=\frac{2}{3}\left(S_{a}+a S_{b}+a^{2} S_{c}\right)
$$

where $a=e^{j 2 \pi / 3}$, when $S_{i}=1$ means $S_{i}$ on, $\bar{S}_{i}$ means off, and $i=a, b, c$. The voltage vector $v$ is related to the switching state $S$ by

$$
v=V_{d c} S
$$

where $V_{d c}$ is the dc link voltage.

\section{THE VEHICLE MODEL}

The vehicle considered in the analysis and target for the implementation of the proposed control system is a traction system Figure 2. Starting from an usual vehicle structure, some adaptations are in course with the objective of introducing two independent front wheels propulsion system using electric drives.

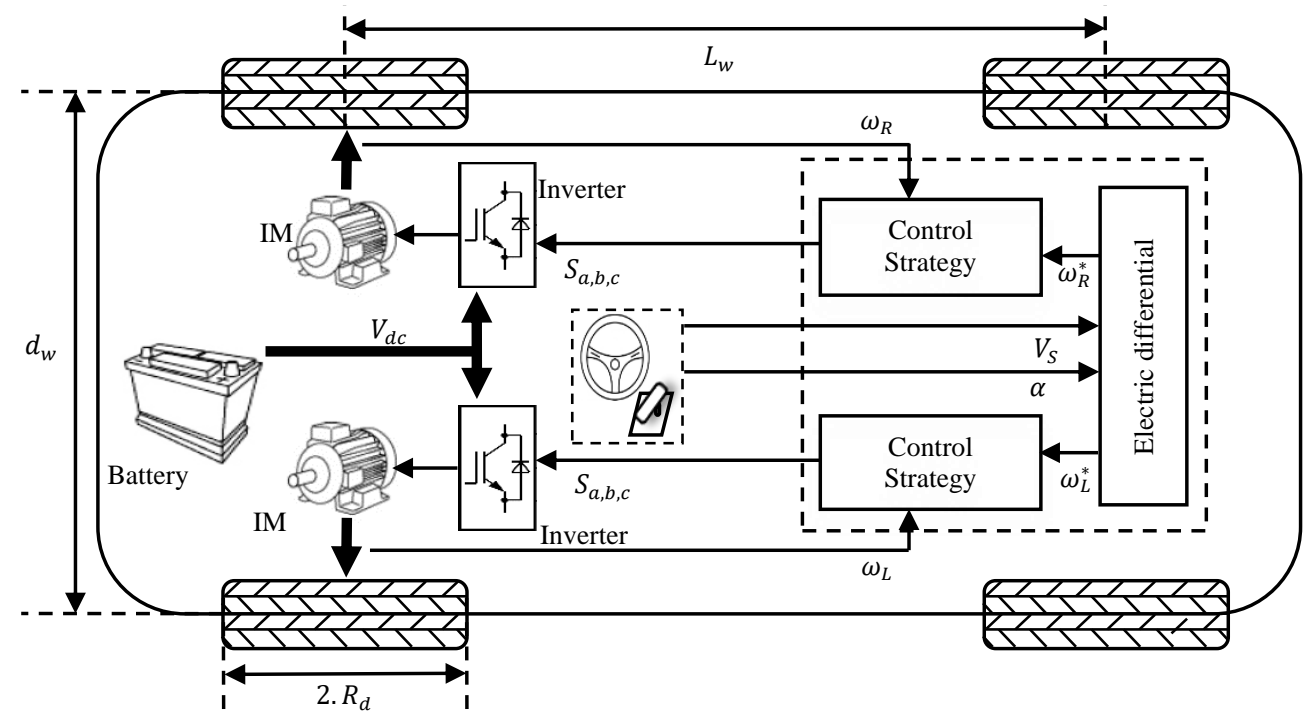

Figure 2. Vehicle geometry and driving wheels control system

\section{DIFFERENTIAL SPEED REFERENCES COMPUTATION}

It is possible to determine the speed references versus the requirements of the driver. When the vehicle arrives at the beginning of a curve, the driver applies a curve angle on its wheel. The electronic differential acts immediately on the two motors reducing the driving wheel speed situated inside the curve increasing thereby the speed of the driving wheel outside the curve. The driving wheels angular speeds are as follows $[12,13]$.

$$
\begin{aligned}
& \omega_{r R}=\frac{V_{h}}{R_{d}}+k_{b} \Delta_{\omega} \\
& \omega_{r L}=\frac{V_{h}}{R_{d}}-k_{b} \Delta_{\omega}
\end{aligned}
$$

$k=+1$ corresponding to a choice of the direction of the wheel, $(-1)$ the right turn, and $(+1)$ the left turn. The driving wheel speed variation is imposed by the trajectory desired by the driver. It is given by:

$$
\Delta_{\omega}=\frac{d_{\omega}}{2} \frac{\sin (\delta+\beta)}{l_{\omega} \cos \delta} \frac{V_{h}}{R_{d}}
$$


The correlation between $\alpha$ which is the curve angle given by the driver wheel and $\delta$ of the real curve angle of the wheels is given by:

$$
\delta=\frac{\alpha}{k_{d}}
$$

The speed references of the two motors are:

$$
\begin{aligned}
& \omega_{\mathrm{mR}}^{*}=\mathrm{N}_{\mathrm{red}} \omega_{\mathrm{rR}} \\
& \omega_{\mathrm{mL}}^{*}=\mathrm{N}_{\mathrm{red}} \omega_{\mathrm{rL}}
\end{aligned}
$$

\section{RESISTANT TORQUE OF AN ELECTRIC VEHICLE}

To determine the torque required allowing electric vehicles to overcome the resistance forces, some factors have to be token in consideration, these factors are presented as follow [12, 14, 15]:

\subsection{The rolling resistance}

$$
R R=W_{v} \times C_{r r}
$$

$R R=$ Rolling Resistance

$W_{v}=$ Gross Vehicle Weight

$C_{r r}=$ Co-efficient of Rolling Resistance

\subsection{The grade resistance}

$$
G R=W_{v} \times \sin \theta
$$

$G R=$ Grade resistance

$\theta=$ Grade or inclination angle

\subsection{The acceleration force}

$$
F A=M \times a
$$

$M=W_{v} / g$

$F A$ Acceleration force $m$ mass of the vehicle $g$ acceleration due to gravity $\left(9.81 \mathrm{~m} / \mathrm{sec}^{2}\right)$ $a$ required acceleraion

\subsection{The total tractive effort}

The Total Tractive Effort can be calculated as:

$$
T T E=R R+G R+F A
$$

$T T E=$ Total attractive effort

\subsection{Torque required on the drive wheel}

The torque that is required on the drive wheel will is:

$$
\tau=R_{f} \times T T E \times R_{d}
$$

$\tau=$ Torque

$R_{f}=$ Friction factor that account for frictional losses between bearings, axles etc.

$R_{d}=$ Radius of drive wheel 


\section{PREDICTIVE TORQUE CONTROL OF THE ELECTRIC EV}

The design of the predicted torque control (PTC) technique is represented in Figure 3, it's based on the prediction of the stator current and flux for all feasible voltage vectors in order to regulate the torque in the time period between $k$ and $k+1$, and also a design of a cost function. only the first next voltage vector step is considered in next section [16].

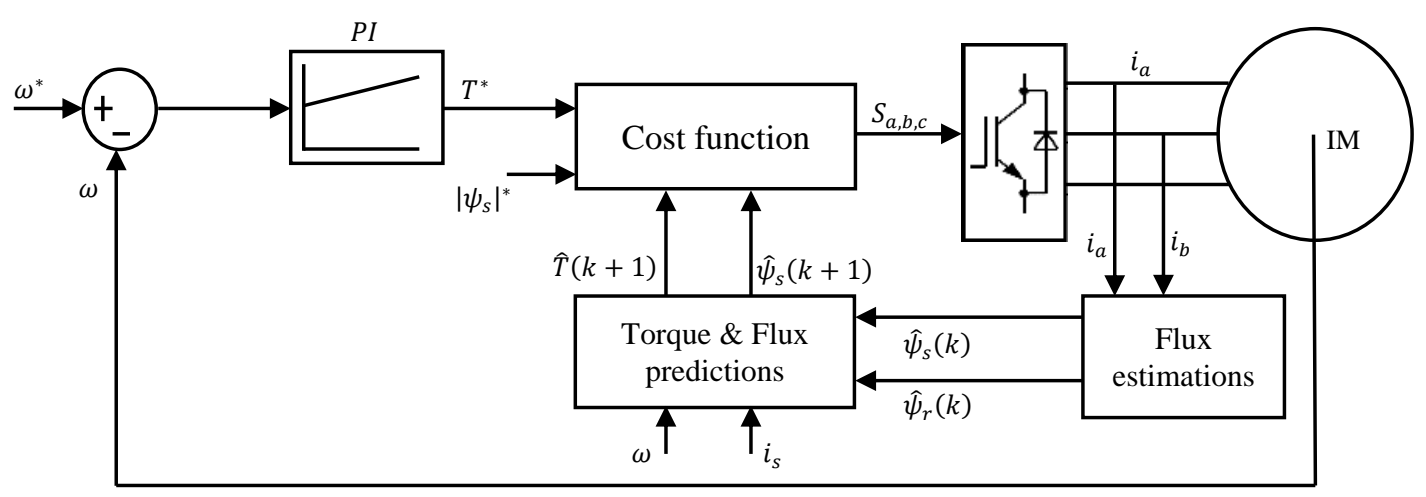

Figure 3. Block diagram of the predictive torque control

The first step stator currents are calculated using equations (1), (3) and (4) from the IM model described in previous section, it can be described as follows:

$$
i_{s}=-\frac{1}{R_{\sigma}}\left(\left(L_{\sigma} \cdot \frac{d i_{s}}{d t}-k_{r} \cdot\left(\frac{1}{\tau_{r}}-j \cdot \omega\right) \cdot \psi_{r}\right)-v_{s}\right)
$$

where $k_{r}=l_{m} / l_{r}, R_{\sigma}=R_{s}+K_{r}^{2} \cdot R_{r}$ and $l_{\sigma}=\sigma \cdot l_{s}$

Using the forward Euler discretization, we can predict the next step value

$$
\frac{d x}{d t} \approx \frac{x(k+1)-x(k)}{T_{S}}
$$

$T_{S}$ is the sampling time of the system.

With (20) and (21), the stator current can be predicted as:

$$
\begin{aligned}
& \hat{\imath}_{s}(k+1)=\left(1-\frac{T_{s}}{\tau_{\sigma}}\right) \cdot i_{s}(k)+\frac{T_{s}}{\tau_{\sigma}} \frac{1}{R_{\sigma}} \cdot\left[K_{r} \cdot\left(\frac{1}{\tau_{\sigma}}-j \cdot \omega(k)\right) \cdot \psi_{r}(k)+v_{s}(k)\right] \\
& \tau_{\sigma}=\sigma l_{s} / R_{r}
\end{aligned}
$$

The next-step stator flux $\hat{\psi}_{s}(k+1)$ and the electromagnetic torque $\widehat{T}(k+1)$ are calculated, using (21) to discretize the voltage model (1), the stator flux prediction obtained is as follows [7]

$$
\widehat{\psi}_{s}(k+1)=\widehat{\psi}_{s}(k)+T_{s} \cdot V_{s}(k)-R_{s} \cdot T_{s} \cdot i_{s}(k)
$$

According to (5), with predictions of the stator flux (23) and the predicted current (21), the electromagnetic torque obtained:

$$
\widehat{T}(k+1)=\frac{2}{3} \cdot p \cdot l_{m}\left\{\hat{\psi}_{s}(k+1)^{*} \cdot \hat{\imath}_{s}(k+1)\right\}
$$

with the predicted values of torque and stator flux, electric torque and stator flux magnitude control is obtained by the minimization of a cost function $F$ for which the inputs are the torque reference $T^{*}$, the predicted torque $\hat{T}(k+1)$, reference stator flux $\left|\psi_{s}\right|^{*}$ and the predicted stator flux $\left|\hat{\psi}_{s}(k+1)\right|$ magnitudes,

$$
F=\frac{\left[\left(T^{*}-\widehat{T}_{j}(k+1)\right]^{2}\right.}{T_{n}^{2}}+\frac{\left(\left|\psi_{s}\right|^{*}-\left|\widehat{\psi}_{s j}(k+1)\right|\right)^{2}}{\left|\psi_{s n}\right|^{2}}
$$


where, $j=0 \ldots 6$, corresponding to the 7 different voltage vectors of the two level source inverter applied in this system; for each stator voltage vector available, this cost function $F$ is evaluated, and the stator voltage $\vec{v}_{s}[k]$ producing the minimum cost is selected to be applied on motor terminals. Weight gains $T_{n}$ and $\left|\psi_{s n}\right|$ correspond to the rated torque value and flux reference during normal speed operation [17].

\section{SIMULATION RESULTS}

Using the model shown in Figure 3, we conducted simulations; in the interest of characterise the driving wheel system behaviour. The Figure 4 represents the vehicle speed response using classic DTC and PTC.

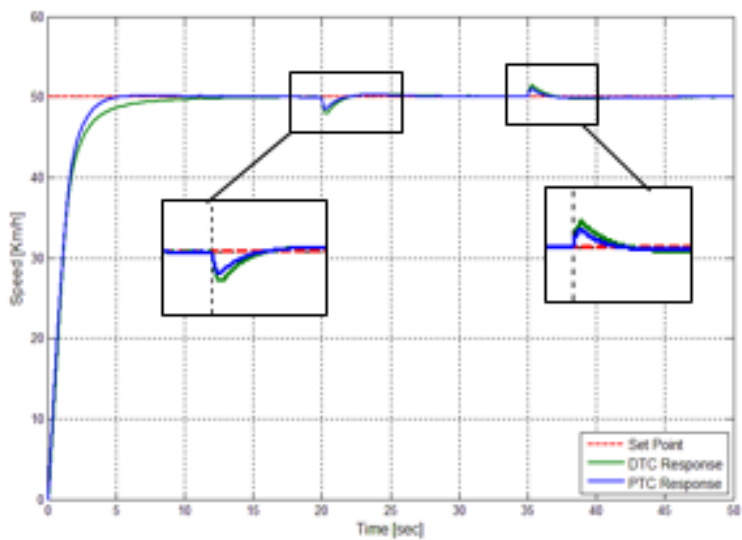

Figure 4. Vehicle speed response using classic DTC and PTC control

The next figures present vehicle speed variation for PTC "Predictive Torque Control". we use the PTC algorithm, instead of using classical control, in the interest of improving the control loop robustness. The capacity of the algorithm to maintain ideal trajectories independently of the external disturbances and the parameter variations which makes the robustness therefore the advantage of this control. To show the effect of disturbances by resistive torque of PTC control, Figures below shows the system responses of the two cases.

\subsection{Case of straight way}

In this test, we have two cases, the first one is straight road without a slope shown in Figures 5, 7, 9; than we have straight road with $10 \%$ a slope shown in Figures 6, 8, 10; the system is submitted to the same speed step. Only a change of the developed motor torque is noticed since the driving wheels speeds stay always the same and the road slope does not affect the control of the wheel. The slope effect results in high improvement in the electromagnetic motor torque.

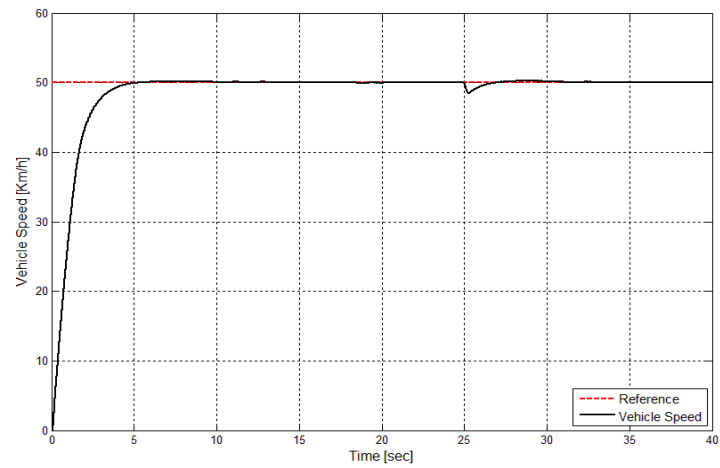

Figure 5. Vehicle speed in a straight way without slope

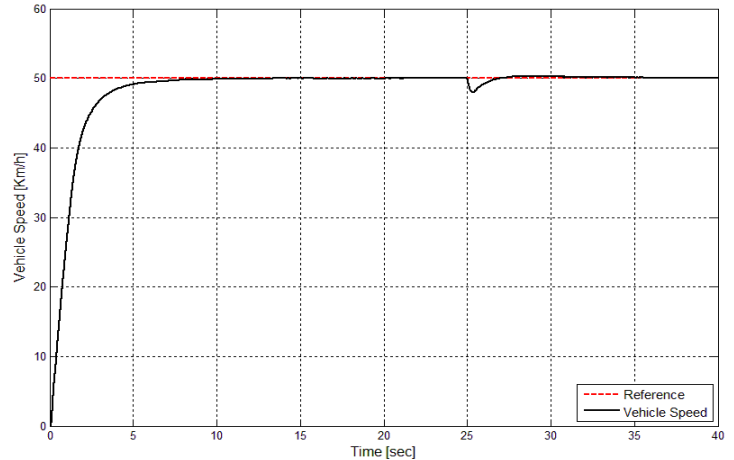

Figure 6. Vehicle Speed in a straight way with slope 


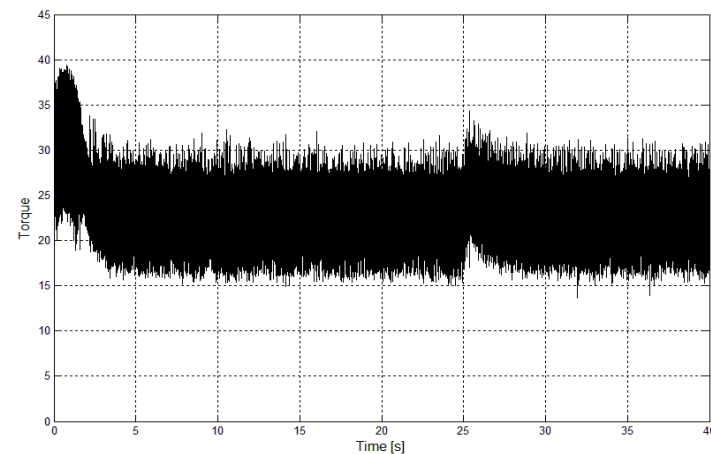

Figure 7. IM Torque in a straight way without slope

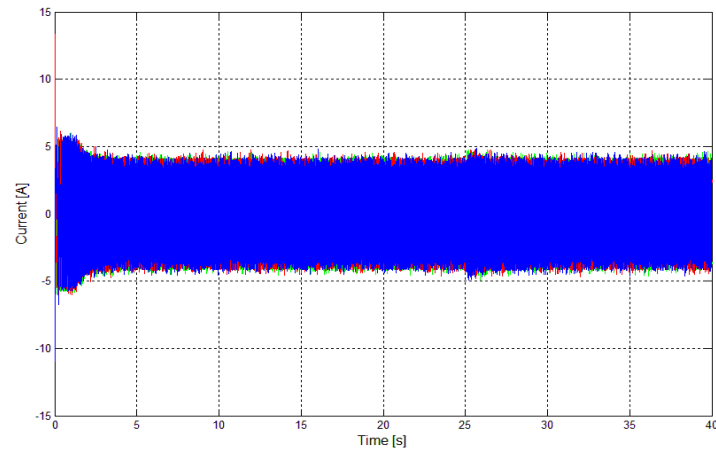

Figure 9. IM Currents in a straight way without Slope

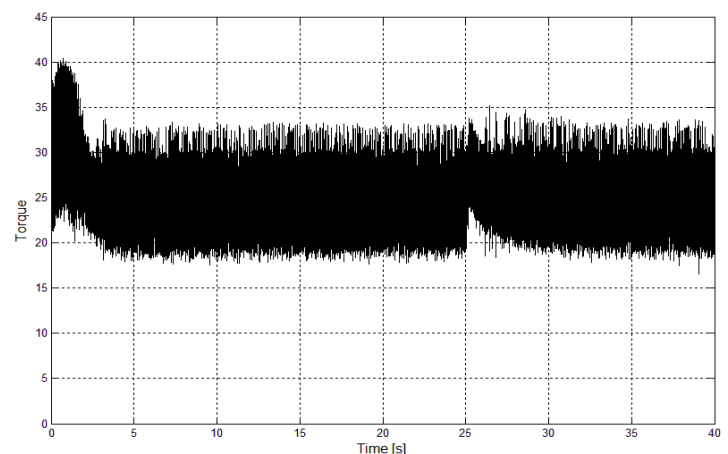

Figure 8. IM Torque in straight way with slope

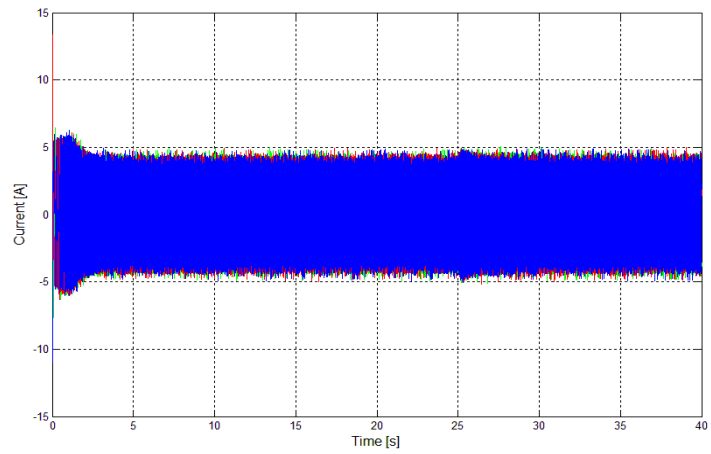

Figure 10. IM Current in a straight way with Slope

\subsection{Case of curved way}

The vehicle is driving on a curved road on the left side with $50 \mathrm{~km} / \mathrm{h}$ speed. We assume that two motors are not disturbed. The driving wheels follow different paths, and they turn in the same direction but with different speeds due to the electronic differential who acts on the two motor speeds by decreasing the speed of the driving wheel on the left side situated inside the curve, and on the other side by increasing the wheel motor speed in the external side of the curve. In this test, we have two cases, the first one is a curved road without a slope shown in Figures 11, 13, 15 ; than we have curved road with $10 \%$ a slope shown in Figures 12, 14, 16.

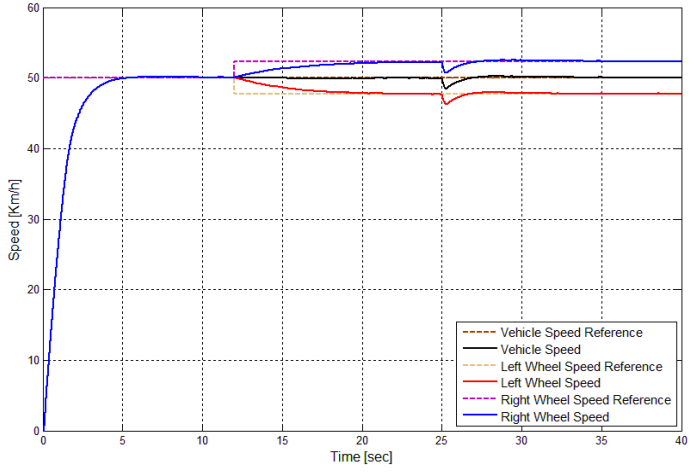

Figure 11. Vehicle's wheels speed in a curved way without slope

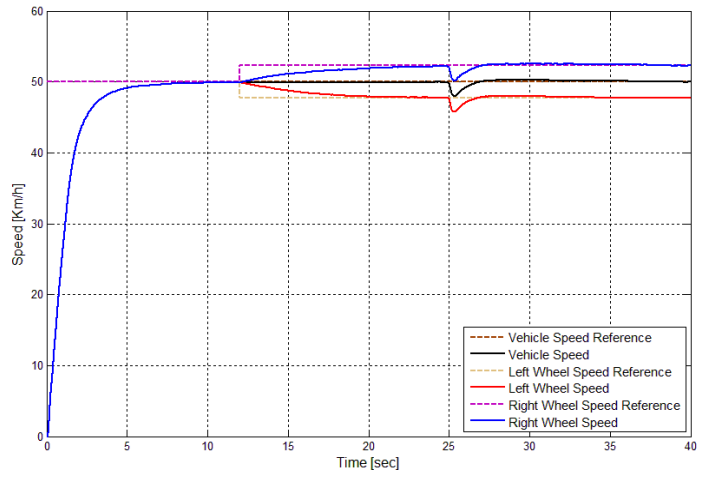

Figure 12. Vehicle's wheels speed in a curved way with slope 


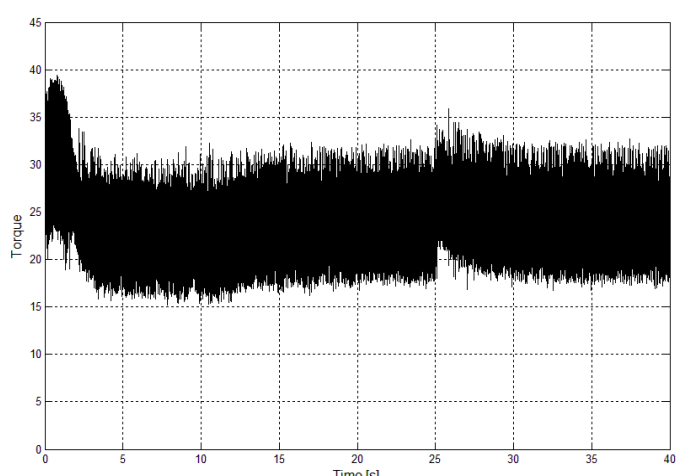

Figure 13. Right IM Torque in a curved way without Slope

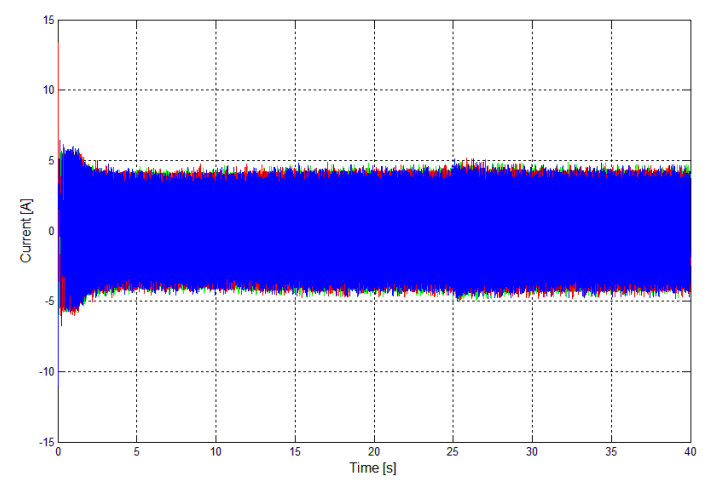

Figure 15. Right IM's stator Currents in a Curved way without Slope

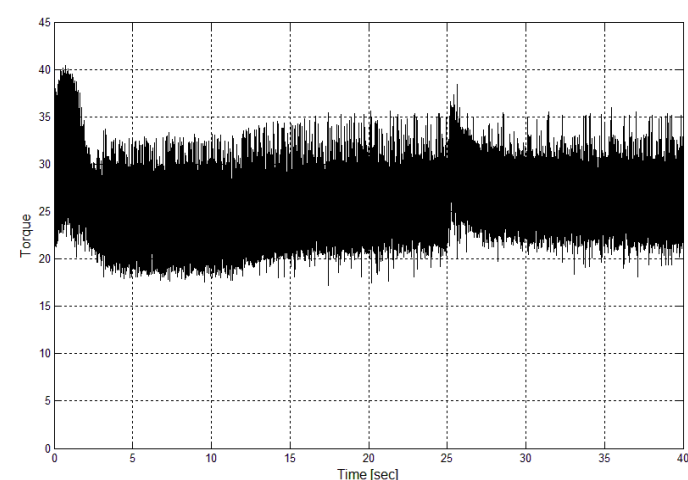

Figure 14. Right IM Torque in a curved way with Slope

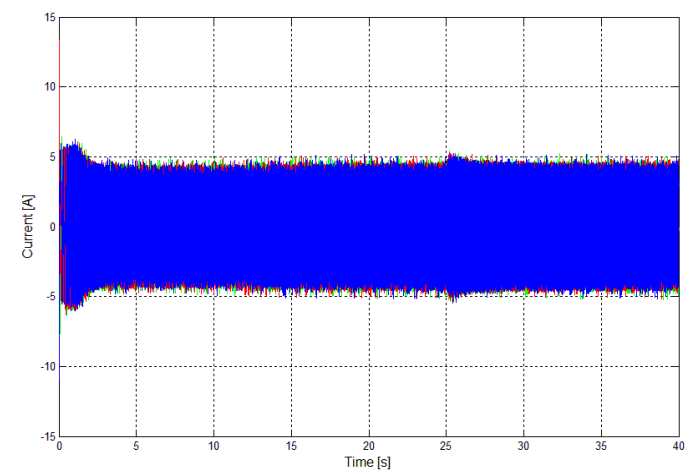

Figure 16. Right IM's stator Currents in a curved way with Slope

Although that the control with Predictive Torque controller offers better performances in both control and tracking, but these figures show that the effect of the disturbance is very low in the case of the PTC. Moreover to these dynamic performances, the imposed constraints are respected by the driving system such as the robustness and parameter variations.

\section{CONCLUSION}

In this paper, the predicted torque control technique has been applied and simulated to control two induction machines with electronic differential used in the structure of a traction system for an electric vehicle. PTC is a simple technique based on two conditions; the first one is DTC switching table, and the second one is the prediction of the current, torque and flux next step. The result shows that this control provides a robust control; this advantage gives PTC method very good performances in both steady and transient states. In addition to that; the PTC techniques shows better torque and speed response and a more flexible control scheme than DTC. This paper gives an instruction for the selection of MPC methods for engineering practices.

\section{REFERENCES}

[1] X. Shi and M. Krishnamurthy, "Digital Control of Induction Machine--A Potential Backup Control Strategy for Fault Tolerant Control in Electric Vehicle Applications," IEEE Journal of Emerging and Selected Topics in Power Electronics, vol. 2, pp. 651-658, Sep 2014.

[2] T. Furnya, et al., "Implementation of advanced adhesion control for electric vehicle," in Proc. IEEE Workshop Advanced Motion Control, vol. 2, pp. 430-435, 1996.

[3] Y. Hori, et al., "Traction Control of Electric Vehicle: Basic Experimental Results Using the Test EV "UOT Electric March," IEEE Transactions On Industry Applications, vol. 34, pp. 1131-1138, 1998. 
[4] M. Doumiati, et al., "Dynamics Control of an In-Wheel Electric Vehicle with Steer-by-Wire," 17th International IEEE Conference on Intelligent Transportation Systems (ITSC), pp. 348-353, Oct 2014.

[5] D. Casadei, et al., "FOC and DTC: Two Viable Schemes for Induction Motors Torque Control," IEEE Transactions On Power Electronics, vol. 17, pp. 779-787, Sep 2002.

[6] A. Ammar, et al., "Closed loop torque SVM-DTC based on robust super twisting speed controller for induction motor drive with efficiency optimization," International Journal of Hydrogen Energy, vol. 42, pp. 17940-17952, Jul 2017.

[7] F. Wang, et al., "Model Based Predictive Direct Control Strategies for Electrical Drives: An Experimental Evaluation of PTC and PCC Methods," IEEE Transactions on Industrial Informatics, vol. 11, pp. 671-681, Jun 2015.

[8] A. Ammar, et al., "Predictive Direct Torque Control with Reduced Ripples and Fuzzy Logic Speed Controller for Induction Motor Drive," The 5th International Conference on Electrical Engineering - Boumerdes (ICEE-B), Algeria, Oct 2017.

[9] J. L. D. Madrid, et al., "Predictive Control of a Furuta Pendulum," IEEE 3rd Colombian Conference on Automatic Control (CCAC), Oct 2017.

[10] M. Preindl and S. Bolognani, "Model Predictive Direct Torque Control With Finite Control Set for PMSM Drive Systems, Part 2: Field Weakening Operation," IEEE Transactions On Industrial Informatics, vol. 9, pp. 648-657, May 2013.

[11] Md. Habibullah, et al., "A Simplified Finite-State Predictive Direct Torque Control for Induction Motor Drive," IEEE Transactions On Industrial Electronics, vol. 63, pp 3964-3975, Jun 2016.

[12] A. Nasri, et al., "Two Wheel Speed Robust Sliding ModeControl for Electric Vehicle Drive," Serbian Journal of Electrical Engineering, vol. 5, pp. 199-216, Nov 2008.

[13] J. Larminie and J. Lowry, "Electric Vehicle Technology Explained," John Wiley \& Sons, England, 2003.

[14] M. khessam, et al., "Fuzzy Adaptive Control for Direct Torque in Electric Vehicle," International Journal of Power Electronics and Drive System (IJPEDS), vol. 4, pp. 557-566, Dec 2014.

[15] S. Chauhan, "Motor Torque Calculations For Electric Vehicle," International Journal Of Scientific \& Technology Research, vol. 4, pp. 126-127, Aug 2015.

[16] B. Zhu, et al., "Predictive Torque Control with Zero-Sequence Current Suppression for Open-End Winding Induction Machine," 2015 IEEE Industry Applications Society Annual Meeting, Dec 2015.

[17] H. Miranda, et al., "Predictive Torque Control of Induction Machines Based on State-Space Models," IEEE Transactions On Industrial Electronics, vol. 56, pp 1916-1924, Jun 2009.

\section{BIOGRAPHIES OF AUTHORS}

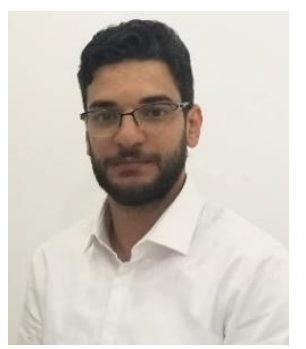

Mohammed El Amin Abdelkoui was born in 1990 at Bechar-Algeria, received the state Master degree in Automatic \& Telecommunication engineering in 2013 from the University of Tahri Mohammed of Bechar, Algeria.He's currently preparing his Ph.d. degree in electronic engineering.

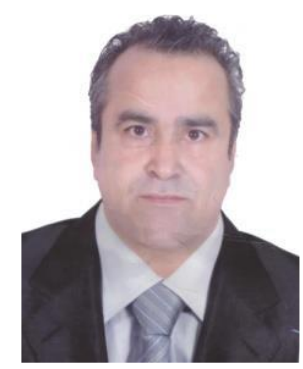

Abdeldjebar Hazzab received his State Engineer, M.S., and Ph.D degrees in Electrical Engineering from the Electrical Engineering Institute of The University of Sciences and Technology of Oran (USTO), Algeria in 1995, 1999, and 2006, respectively. He is currently a Professor of Electrical Engineering at the University of Bechar (Algeria), where he has been the Director of the Research Laboratory of Command, Analyses, and Optimization of ElectroEnergetic Systems since 2009 at 2014. His research interests include power quality, modeling, modern controller and observer design for nonlinear systems, control of power electronics and multidrive systems, control of power electronics, multidrive systems and electrical vehicle, and adaptive control and nonlinear systems diagnostic, adaptive control, neural networks and fuzzy logic systems. 